\title{
The Design and Develop Computer based MIS for Schools in North Gujarat Area that Cover all Activities of School and Help to Management for Decision Making using Basic to Advance Technology
}

\author{
Ghasura Sahidkhan Sabbirkhan \\ Software Developer \\ Worked as Assistant Professor B.K Mehta IT Centre, \\ Palanpur - 385001
}

\section{ABSTRACT} The role of MIS in education environment has evolved
over time to become an vital part of its education process in India. the existing information system and also those of computerized MIS currently under implementation do not provide institution wise information, they are of limited use to the extent of generating aggregate data. Therefore, the scope of MIS needs to be expanded, so that indicators of quality of education can be generated and online information be made available not only to head master and teachers but also to those who are responsible for monitoring quality of education [18]In India the Ministry of Human recourses development and government of India use Unified District Information System for school education system (U-DISE) is offline based application software that use for handling MIS for secondary and Primary Scholl Education. This MIS data used by projects like Sarva shiksha Abhiyan, Rashtriya Madhya Shiksha Abhiyan etc. [1]. MIS can help us in many ways in the field of education. . It intends to support School management for provide information timely, accurate and can handle School Management Activities It covers School Management area Like Maintain Students Record, attendance, Examination, Time Table, Mess Management, Employee Payroll Transportation Management, Administrative work Different Performa's, different reports etc. It can help us store student related information for decision making that helpful for students development and progress in the class, and further helps in planning their placement activity better, and also making its footprint on managing aluminum long run, and much more. MIS also help in managing human resources, experts and overall knowledge management $t$ in the organization. There are many other areas in education that could be handled better with the help of MIS, like Research and consultancy work, infrastructure, corporate lessoning, conferences, journals, etc [2]. The study attempts to highlight the design and developing school management information system in North Gujarat area . It intends to determine how the management information system helps an education to perform effectively. As concerning with this area some school trust have a poor economical condition whereas some have good condition so it needed to recommends that education MIS system should be design and develop basic to advanced level for this area. For the School which one have a low budget it should be develop by common software package ie data stored in excel as various Performa that data can easily migrate to advanced technology in future when needed. For Scholl which have good economic condition here it is focus that development of school MIS using advanced technology.
\end{abstract}

\section{General Terms}

Web services for sharing data, decision making, Performa's, Management information system in education, Data processing

\section{Keywords}

Expert system, Cloud Computing, 2D barcode, Open system, Closed system, ICT, Webservices

\section{INTRODUCTION}

\section{Overview of Management Information System}

A system to convert data from internal and external sources into information and to communicate that information in an appropriate form to managers at all levels in all function to enable them to make timely and effective decision for Planning, Directing and controlling activities for which they are responsible is called as MIS.MIS have three subcomponent management,information,system

- Management:

- Information

- System

\section{Management}

Focusing on the ultimate use of such information systems for managerial decision making

\section{Information}

The information is refer to as process data .The need and types of information vary between one users to other users. So Information is critical .One user have a information which is not demand by other users, Sometimes some information demand by user but in real it is not needed. Sometimes need for actual information but it is not available. If Information Improves the resulting decisions otherwise it has no value.

\section{System}

It is focus on integration and Holistic view. It is collection of Component that work together to realize some objective forms a system. Systems have three components Input, Processing and Output.

In short MIS refer as right information to the right person, at the right place, at the right time, at the right form, at the right cost [16]. 


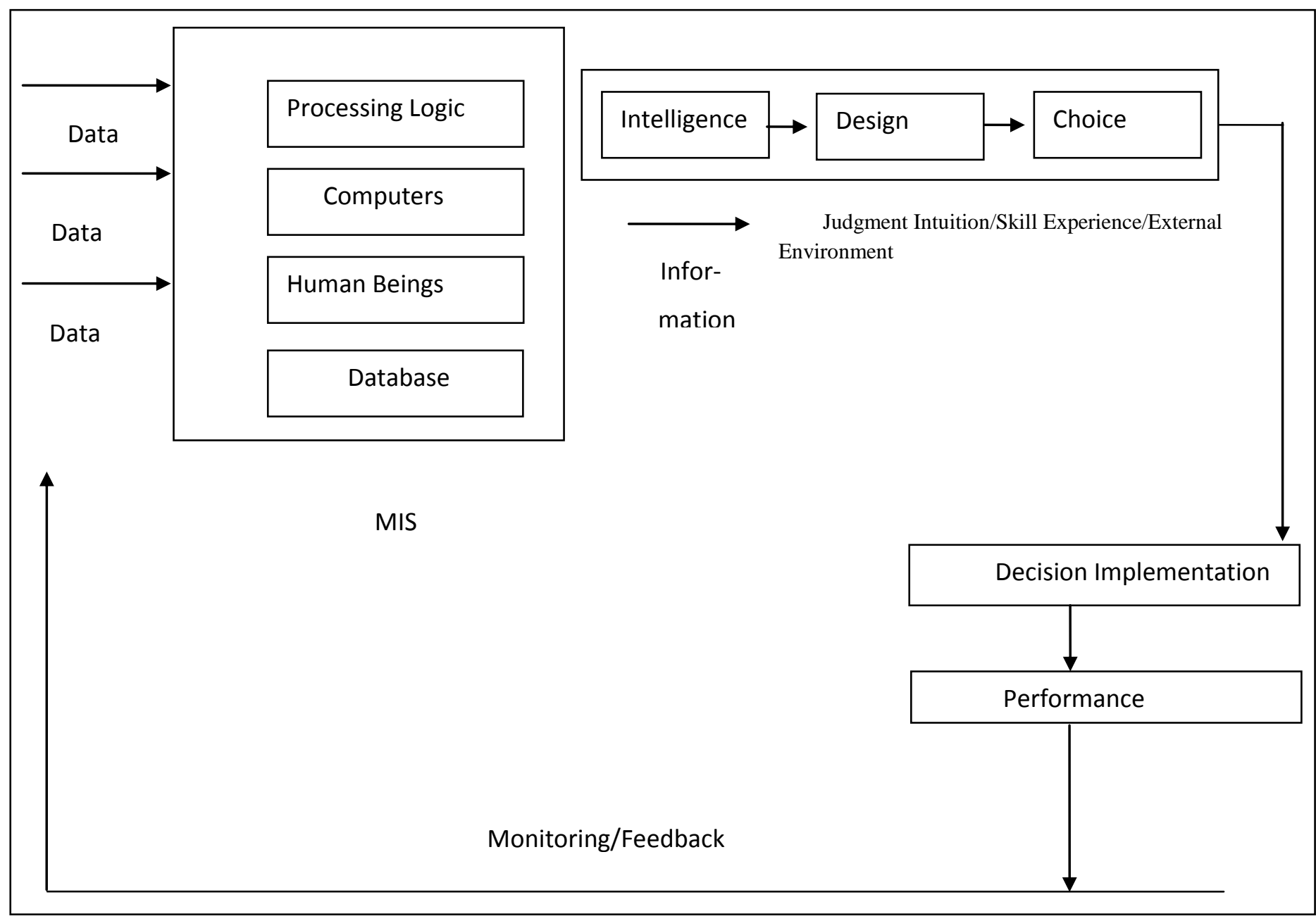

Figure1Concept of MIS

Now, the role of IT effect to all the world and it become part of human life so It become necessary to accept broader reform efforts (Wider modernization efforts across the government tend to generate calls for greater use of technology and performance Measurement at the school level).

There are three major area that IT influence on management information system
1. Data processing
2. Office Support System
3. End user System.

\subsection{MIS with Education System}

Education system is the Heart of any country so at the school level information is needed for decision making to parents,teacher,school head, Inspector or supervisor ,education officer etc.school MIS help out to maintain interrelationship between parents and principal, Interrelation between parents and homeroom teachers ,Interrelations between Parents and subject matter teachers, Interrelations between parents and department head, Interrelations between parents and grade level coordinators, Interrelations between parents and the school as an institution,

Interrelations between parents and their children Interrelations between parents-parents interrelation [3].

Developing system first concept should be clear that which information required for which entity .Developing MIS should take care that developing in the way that Linkage between subsystems should be taken and easily slip into small system. IT should be holistic view not part of System. IS allowing information flow between different areas so reducing need of face to face communication. IS looks at social and behavioral characteristic of number of organization.

Objective are clearly before they are used. What must be done must be declared before considerably how it should be done. Before Developing MIS it should be know about constraint to achieve its objective .DSS it is Interactive computer based system design to help the decision maker to use all resources available and make use in decisionmaking. Effective Decision making demand accurate, timely and relevant information [4] ,information resource is one of the major issues and indices of university (education) planning. Where the relevant information required for planning are not available at appropriate time, there is bound to poor planning inappropriate decision making ,poor priority needs defective programming or scheduling of activities [5] DSS Gives its users access to varieties of data sources modeling techniques and Stored domain knowledge via an easy to use graphical user interface (GUI) [6].A useful DSS is able to complete and extract meaningful information from row data and to suggest potential solution for users to make informed decision. DSS can be also defined as model based or knowledge based system intended to support decision making in semistructured or unstructured situation. 


\subsection{Research Technique}

Use Sampling Technique and collect information from Various Schools using questionnaire. Use SPSS software for calculating the three questions.

1. How many schools have Average, Weak and Good economical region [Figure 5].

2. How many Weak, Average and Good economic Condition school s use the current Technology like Excel Performa's, Desktop application etc [Figure 6].

3. How many Weak, Average and Good economic schools are ready for accepting Advance technology?[ [Figure 7]

\section{PROBLEM FACTOR}

Problem factor represent that during developing MIS what problem should be considerable and as also about the problem that face in North Gujarat area.

\subsection{Problem of Implementing a Computer based Management Information System}

Before Understanding the School MIS Problem it e should be consider MIS problem

That Describe by author Dincion[1970] identified some major factor that determine whether the implementation of a new MIS will be resisted and to what event they are

Disruption of established departmental boundaries:-The establishment of a new MIS often result in change in several organization units.

Participating: In designing and implementing MIS features users should be made members of the MIS team operating managers in particular they should have a particular say in the item to be included .The disposition of the entire information and possible job modification, if the entire design and implementation process is taken over by technology

Communication: The aim and characteristic of the system should be communicated to all members of the MIS team as well as the users.

Redefinition of performance measurement:-A new MIS may modify a manager's job to the point where old methods of performance evaluation no longer apply or is no longer applicable. For this reason MIS calls for proper evaluation.

\subsection{Update Problem}

Organization should update according to need but One Whole System is Interconnection with other correlated sub system. The Term System Approach says that changing in one Part of system affect system whole. The need of Update depend on different factor like change in Technology, change in Staff of Management ,Government Policy ,Changing in Location, The system can two type $=$ Open and Closed

Closed System:-It is one that isolated from its environment. System neither effect to neither environment nor environment effect to system.

Open System:-Which Intact with environment It receives inputs and Influences from environment and Passes back output and influences to the environment.

\subsection{Problems of developing school MIS in North Gujarat are}

The school MIS cannot useful with Performance data, Cost Accounting , and not able to monitoring of Internal management initiative as concerning with north Gujarat area it have above problem in some schools. Lack of Management involvement design with MIS,Narrow and improper emphasis of Computer System, Lack of management knowledge of computer, Lack of top Management Support., Lack of Resource available

\section{MIS DEVELOPMENT LIFE CYCLE}

According to Concerning with SDLC and some MIS for design and develop point that define by different author by using their view it's makes help for create own step for design and developing the school MIS it is define in figure 2.Tthe major point define [7][8][9] System Planning, System Analysis, System Design, System Implementation, System Operation, Support and Security, System Application, Access Feasibility, Information Requirement Analysis, Conceptual Design, Physical Design, System Specification, Program Specification, Develop the system, Install the System, Conduct Awareness \& Training, Operate the system, Review \& Audit, Strategic Planning, Requirement Analysis, Resource Allocation, Project Planning. 


\section{STEPS FOR DESIGN AND DEVELOPMENT OF SCHOOL MIS}
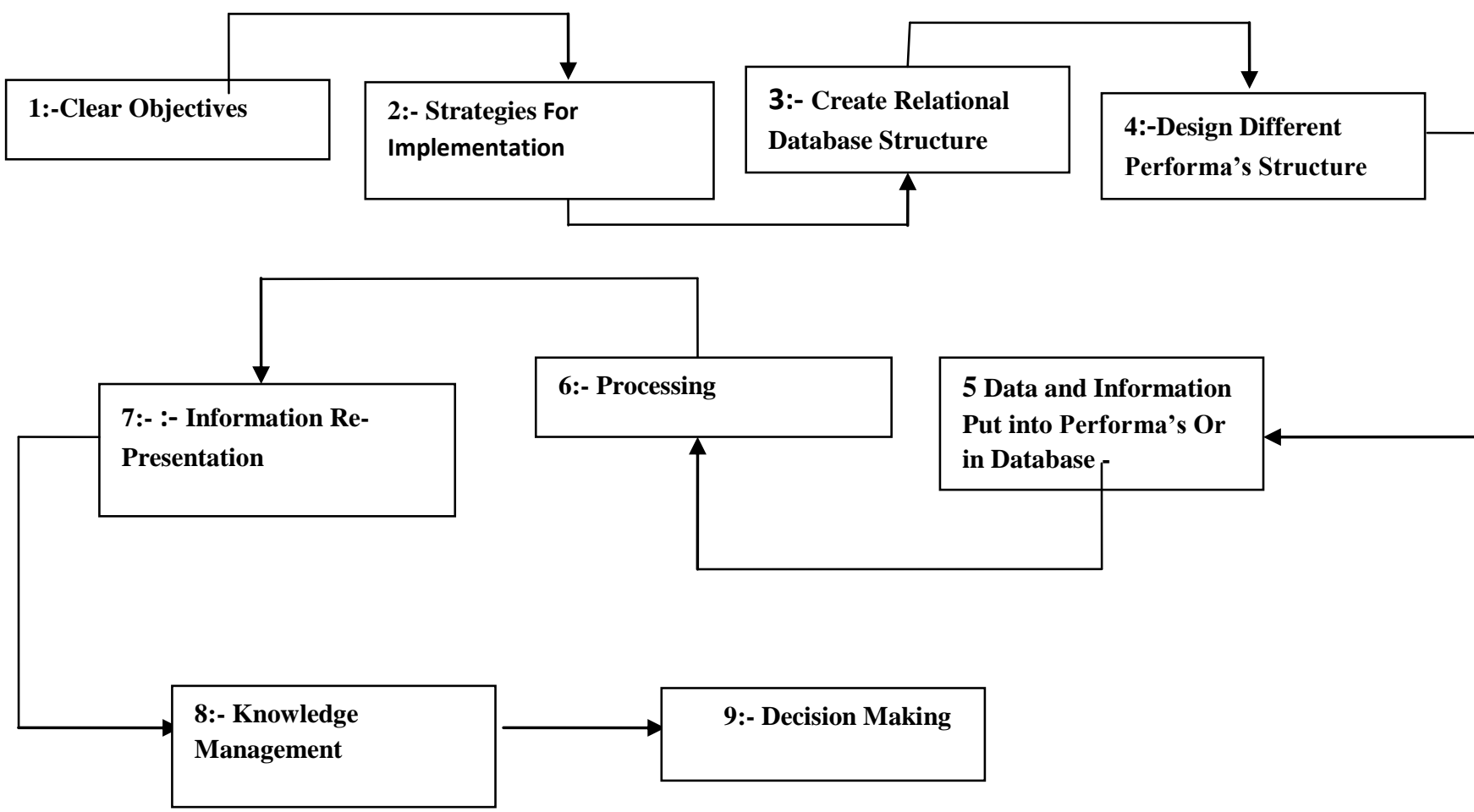

Figure2 .Steps for Creating School MIS

\subsection{Clear Objectives}

Your mission and objectives clearly define for making Education MIS system. during defining Your objective you should be consider short and Long term Planning.

The understanding for making system should be clear in both sides.

\subsection{Strategies for Implementation}

In this step define strategies for Implementing System. You also verify available resources for Implementation of system but At beginning It is difficult to predict available resources and Cost

\subsection{Create Relational Database Structure}

Data are Organize into form Row-and Column called table and all Table are collected into call Database. In the Market there are various database tools are available that used for Store data.

Data are permanently stored into database as a periodically database must be take back up so that you can access when physically damage of media.

\subsection{Design Different Performa's Structure}

Design Different Excel template for maintain different data. This method of developing MIS used when Education system Have Less budget for developing MIS.

Instead of Making Any Software Application use Excel Sheet as data storage

Advantage of this system is less cost and not higher Knowledge required for implementing system. and Problem with this system is data searching and accessing become difficult and there is chance of incorrect input of data.
List of Performa's Sheets:-

1. School Detail

2. Student data

3. Class assignment

4. Subject Teacher

5. Class Teacher

6. Lesson Plan

7. Secondary school subject wise Result

8. Higher secondary school subject wise result

9. Committees

10. Student Personnel House System Detail

11. Student Medical care

12. Mess menu

13. Daily Student Attendance

14. Rate List for Supplier

15. Monthly Expenditure

16. Monthly stock Management

17. Safety and Security in School

18. Daily School report

19. School wise staff detail

20. Extra training

21. Finance Record of Employer 

22. Infrastructure
23. Send Detail related to Construction
24. Event Celebration
25. Contract-Out-Classes
26. Volunteer Classes etc.

According to my point of view this are the Main Performa's that enough for handling and small scale or Large scale School. This step helpful for only low budget school.

\subsection{Data and Information Put into Performa's Or in Database}

System developer must be Clarify that which data you have to collect and which one are avoid. A manual operation should take place to come out essential information about data collection you can Use any fact finding Technique for collecting data.

Your data must be match with your target requirement. you can share data between step 4.4 to 4.5 or 4.5 to 4.4 vice versa.

\subsection{Processing}

This Step helpful if you develop Software application for those School who have good economic condition.

Here main role of programmer for developing whole system. Programmer should take care to put Validation and that should be prohibit data entry operator for input wrong data. Programmer also responsible for handling any logical error for software application. application able to communicate with three common application development environment desktop, web based and mobile. and also used in advanced technology like cloud computing ,send query to expert system, and use $2 \mathrm{~d}$ barcode authentication system.

\subsection{Information Re-Presentation}

Present Data in to Different Format Report, Chart, or use for analysis and also can be use to teach staff.

\subsection{Knowledge Management}

Before discussing about the knowledge It is requires to understand the different between meaning ok knowledge and information. It is important to know that without information, you will not have knowledge. Information is processed data whereas knowledge is information that is modeled to be useful. You need information to be able to get knowledge. Information deals with the way data is related while knowledge examines patterns within a given set of information. To get knowledge you need some cognitive and analytical ability while for information you do not need cognitive ability. According to David Moon Knowledge management requires tools that focus on the relevancy and accessibility of information and that ability to tailor and present information effectively to people who need it most. He prefers terms such as knowledge sharing or knowledge networking. Knowledge management is a Value -driven organizational process, New business focusing on intellectual assets, New technology of information management, Knowledge based approach of finding compiling and distributing information, it is a new management tool. Knowledge management required in different decision making modes[10].

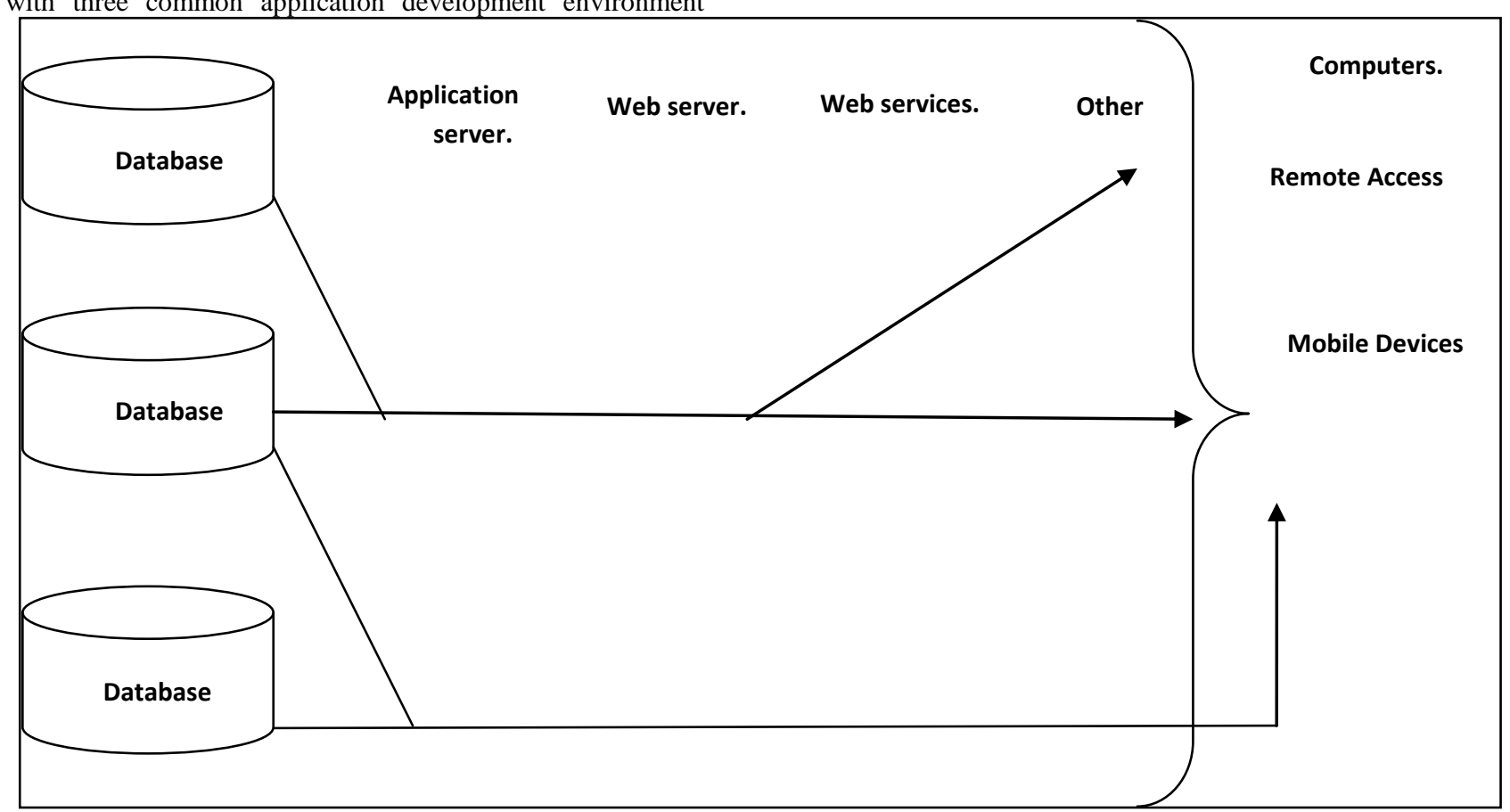

Figure 3:-ICT (information and communicational Technology)

\subsection{Decision Making}

In this step accuracy .reliability of Information that helps for decision maker to take appropriate decision .In school MIS information is used by decision maker like Parents, Teachers, School Head, Education officer and also by Inspector ,supervisor etc.
Parent:-Use Information for periodic Test scores, Monthly/Annual Report, Feeback to Teacher or School Principal .

Teacher:-Student learning achievement and Student attendance record. 
School Head:- Student Learning achievement, Teacher Performance ,Supervisor Observation and community participating report

Education Officer:- Pass information in web portal to education officer, Teacher attendance, Student Learning achievement, School Head Activities, Inspector and supervisor reports etc

Inspector/Supervisor: - Information Use by them for Teacher Performance, Report on class room work and teacher attendance.

\subsubsection{Mobile Decision Making}

The emergence of mobile technologies opened new opportunities and helped developing initiative solution that help decision-maker overcome the barrier of viable accessibility and allow them to perform before when faced with critical event.

The development of mobile application remains a challenges due to the implicitly limitation specific to handheld devices in term of screen size, keyboard dimension, memory and power management [11].

How Mobile use as a decision making Figure 3 represent the how mobile devices and other IT devices use for communication between each others[13].

The system use the ICT web services, web server and remote access for communication between the database server and client machine. The database server in the system can also be directly and remotely accessed by mobile devices through wireless communication.

\section{ADVANCED TECHNOLOGY USE WITH SCHOOL MIS}

\subsection{D barcodes for Security}

Two-dimensional (2D) barcode provide a means of embedding web addresses, text or other data in a camerareadable format. The user of modern mobile phone to scan a 2D barcode with their form and be automatically directed to web page or other data contained within code. A 2D barcode is graphical image that stores information both horizontally-as one dimensional bar codes do and vertically also.2D code can stored up to 7080 character as a your secure data The system provides desktop access to a school management information system. Record based on classic user/password authentication .As the mobile arena is restricted be factors that concern limited keyboard dimension, the developers have Implemented a solution based on the use of standard bi-dimensional (2D) bar codes.

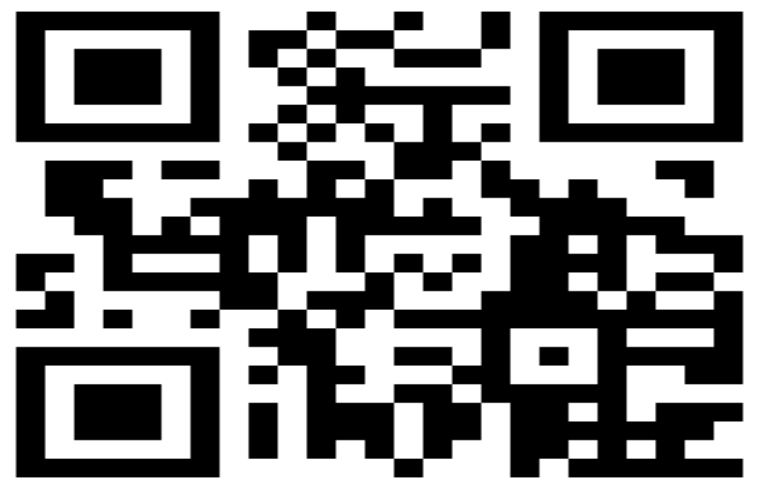

Figure4:-2d barcodes for quick and secure authentication
The 2d Barcodes encodes Student personnel identification information and allow quick and secure 2-Factor authentication

\subsection{Expert System}

As discuss in point number 4.8 (Knowledge management).for accessing the knowledge or share system problem to expert system. An expert system is computer software that attempts to act like human expert on a particular subject area .Expert system are often used to advice non-expert in situation where human expert in unavailable(It may be too expensive to employee or it might be difficult to reach their location). It can also use for student as career guideline [15]. It have commonly three components[12].

- A user Interface

- A knowledge base

- An Interface Engine

A user Interface:- This is the system that allows a non-expert user to query (question) the expert system , and to receive advice. The user-interface is designed to be a simple to use as possible.

A knowledge base:-This is collection of facts and rules .The knowledge base is created form information provided by human experts.

An interface engine:-This acts rather like a search engine, examining the knowledge base for information that matches the user's query.

\subsection{Cloud computing}

The practice of using a network of remote servers hosted on the Internet to store, manage, and process data, rather than a local server or a personal computer.

Cloud computing cover Large number of area like data warehousing, data mining, knowledge management, decision support system, wireless technology, satellite technology etc[14] . So use cloud computing in school MIS as a advanced technology feature this system provides information about production field's data which helps in decision making. This system has alert system for any abnormal situation. This system provide academic expert to school manager or supervisor for advice through video conferencing on demand basis. In the MIS cloud computing provides following Advantage for Using Cloud.

1. It is not required to maintain server ,update Software or security of cloud so maintenances time is save.

2. Purchase Resources in rent so initial cost is reduce.

3. Just need internet connection without worrying of using different device like mobile,Pc,Tablet etc. users able to access data from all over the world .

4. Lost data can easily recover by Cloud.

5. Both External Entity and Internal entity of MIS can use cloud or can Share data Using Cloud Space.

\subsection{Web services}

A web service is any piece of software that makes it self available over the internet and uses a standardized XML messaging system. XML is used to encode all communications to a web service. For example, a client invokes a web service by sending an XML message, and then waits for a corresponding XML response. As all 
communication is in XML, web services are not tied to any one operating system or programming language-Java can talk with Perl; Windows applications can talk with Unix applications [7]. The main use of web services that applications written in different programming languages and running on different platforms can seamlessly exchange data over intranets or the Internet using Web services. Web services are powered by XML and three other core technologies: WSDL, SOAP, and UDDI.
Web services that use for sharing information without worrying different programming language, different hardware, and different Operating system . Concern with Scholl MIS create for application using web services for sharing information among student, parent, management etc by using different device like mobile, computer, Laptop etc.

\section{SCHOOL MIS OVERVIEW}

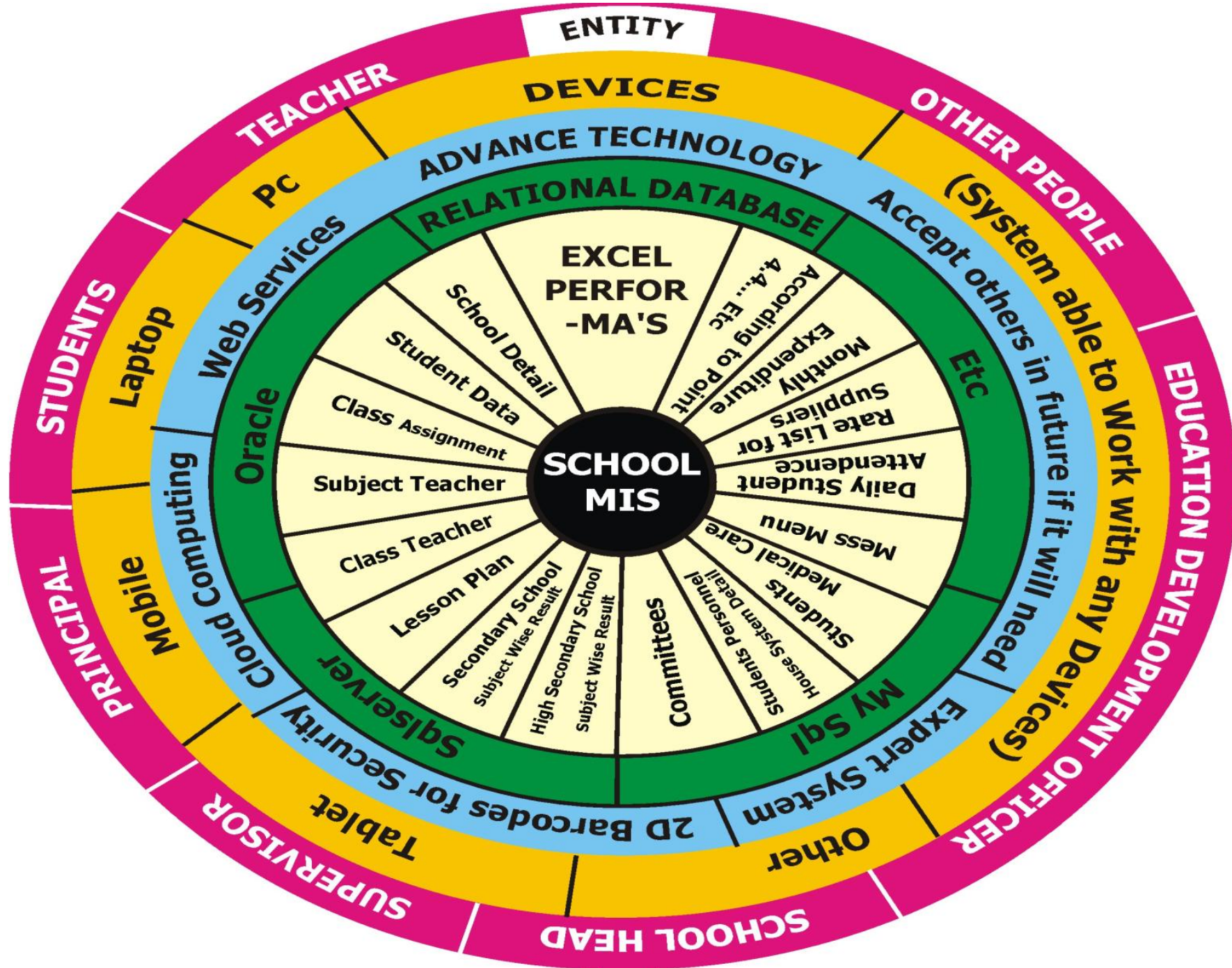

Figure5:-School MIS Overview

The figure 5 Represent about the whole system this structure helpful for both School that have both good and average economical condition. Excel data access by any database technology which able to represent in different devices and useful for different entity.

\section{CONCLUSIONS.}

From above submission it is prove that there are more schools that have average economic condition in North Gujarat area[Figure 7] and they are ever ready to adopt Advance technology[Figure 9] so that $t$ research can be more useful for this area. More ever, other schools are also storing the details/information regarding student in excel Performa's so need to be mentioned possible excel Performa's in above submission and for future if any school desires to use advance technology they can easily import the excel data into advanced technology in this way research can be useful to the schools which desire to migrate to advanced technology. Instead of use school MIS for generating aggregate data or storing information submission represent $t$ that removing communication and sharing information gab among students, parent, teacher, management and expert and connect like Mesh topology use in network. For achieving goal use the step for creating Scholl MIS.

\section{REFERENCES}

[1] MHRD(Ministry of Human Resource Development Government of India )Department of School Education \& Literacy.http.//mhrd.gov.in/rmsa_mis 
[2] Need for MIS in India http:// www.educationforallinindia.com

[3] [Moshe Telem,Sherly Pinto(2004)Information technology's impact on school-parents and parentstudent interrelations: case study]

[4] Aminujm 1986 quality and stress in Nigerian education,Maiduguri Northern Publishing Company

[5] Ajayi I.A and Omirin ,Fadekemi F.(2007) The use of MIS in decision making In the South-West Nigerian Universities

[6] F.G flip(2008) "Decision support and control for largescale complex system ".

[7] MIS system development life cycle

Web services.[http://www.tutorialpoint.com/]

[8] MIS system development life cycle http://deepread.blogspot.in/2011/06/planning-designingand-implementation.html .

[9] MIS system development life cycle kb2.olympia.edu.my/.../mis/16\%20Management\%20Info rmation\%20Sys...]

[10] Zita Zoltayna Paprika(2001)Knowledge management support in decision making

[11] J,Lumsden(2008) J,Lumsden,Handbook of Research on User Interface Design and Evaluation for mobile Technology, Information Science
[12] S. Saraswathi1, M. Hemanth Kumar Reddy2, S. Udaya Kumar3, M. Suraj4, Sk. Khaja Shafi5 (2014) DESIGN OF AN ONLINE EXPERT SYSTEM FOR CAREERGUIDANCE

[13] Jaime Campos \& Om Prakash School of Technology and Design Vaxjo University Sweden Erkki Jantunen VTT Technical Research Centre of Finland (2008) A mobile Maintenance Decision Support system

[14] Raj Kumar Somani1, Dr. Reena Dadhich2(2013) Design of Cloud Computing Based MIS Model for Textile Industries

[15] S. Saraswathi1, M. Hemanth Kumar Reddy2, S. Udaya Kumar3, M. Suraj4, Sk. Khaja Shafi5 (2014)Design of an online expert system career Guidance

[16] Seema sirpal University of Delhi Community Members http://people.du.ac.in/

[17]Yusuf Munirat(2014)The Impact of Management Information System(MIS) on the Performance of Business Organization I Nigeria

[18]Arun c Mehta(2015)Need of Developing Local Information System(LIS) to monitor Factors of Effectiveness

\section{APPENDIX}

\section{how many school have weak, average and good economical region ?}

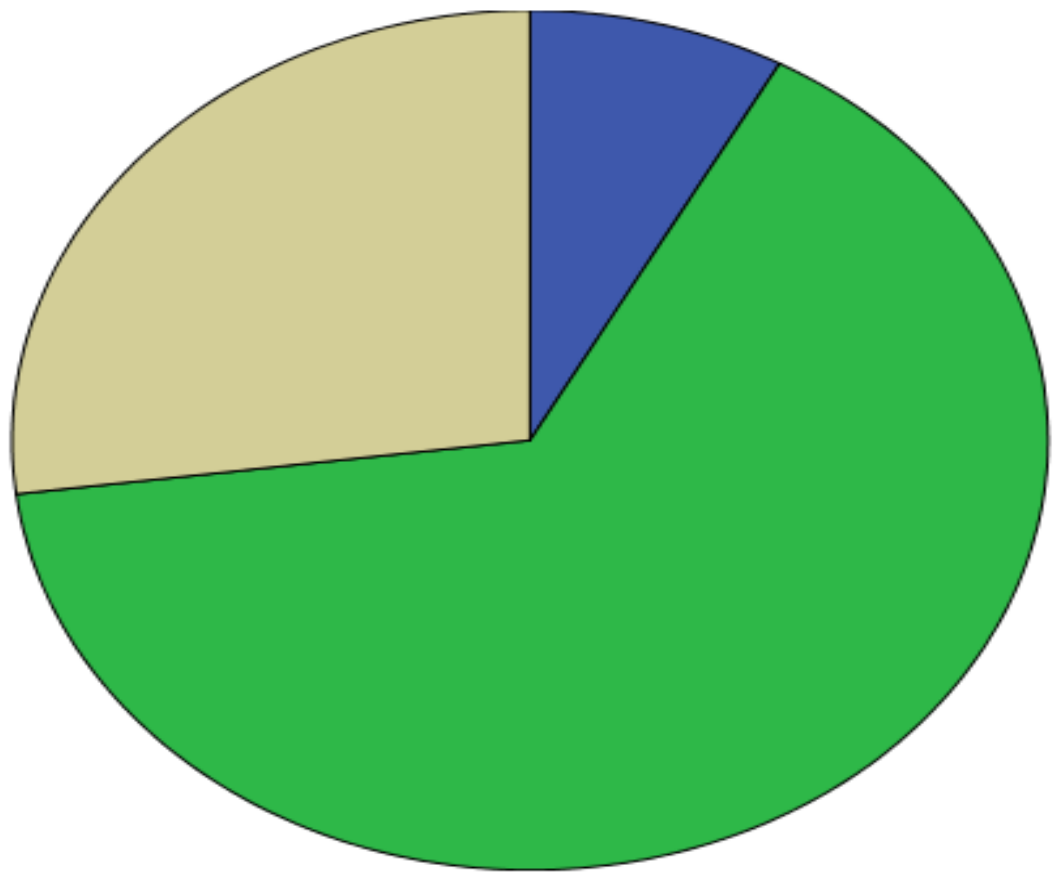

$\square$ weak economica region $\square$ average economical regio $\square$ good economical region

Figure5:-Pie chart that Represent School that Have Weak, Average and Good economical situation 


\begin{tabular}{|c|c|c|c|c|c|c|}
\hline \multicolumn{7}{|c|}{ Case Processing Summary } \\
\hline & \multicolumn{6}{|c|}{ Cases } \\
\hline & \multicolumn{2}{|c|}{ Valid } & \multicolumn{2}{|c|}{ Missing } & \multicolumn{2}{|c|}{ Total } \\
\hline & $N$ & Percent & $N$ & Percent & $N$ & Percent \\
\hline $\begin{array}{l}\text { uses of technology in } \\
\text { schools * how many } \\
\text { school have weak, } \\
\text { average and good } \\
\text { economical region? }\end{array}$ & 100 & $100.0 \%$ & 0 & $.0 \%$ & 100 & $100.0 \%$ \\
\hline
\end{tabular}

uses of technology in schools * how mamy school have weak, average and good economical region ? Crosstabulation

\begin{tabular}{|c|c|c|c|c|c|c|}
\hline & & & \multicolumn{3}{|c|}{$\begin{array}{c}\text { how many school have weak, average and good } \\
\text { economical region? }\end{array}$} & \multirow[b]{2}{*}{ Total } \\
\hline & & & $\begin{array}{l}\text { weak } \\
\text { economica } \\
\text { region }\end{array}$ & $\begin{array}{l}\text { average } \\
\text { economical } \\
\text { region }\end{array}$ & $\begin{array}{l}\text { good } \\
\text { economical } \\
\text { region }\end{array}$ & \\
\hline \multirow{6}{*}{$\begin{array}{l}\text { uses of technology in } \\
\text { schools }\end{array}$} & \multirow[t]{2}{*}{ excel perfoma } & Count & 8 & 65 & 5 & 78 \\
\hline & & Expected Count & 6.2 & 50.7 & 21.1 & 78.0 \\
\hline & \multirow[t]{2}{*}{ desktop application } & Count & 0 & 0 & 9 & 9 \\
\hline & & Expected Count & .7 & 5.8 & 2.4 & 9.0 \\
\hline & \multirow[t]{2}{*}{ other (manually) } & Count & 0 & 0 & 13 & 13 \\
\hline & & Expected Count & 1.0 & 8.4 & 3.5 & 13.0 \\
\hline \multirow[t]{2}{*}{ Total } & & Count & 8 & 65 & 27 & 100 \\
\hline & & Expected Count & 8.0 & 65.0 & 27.0 & 100.0 \\
\hline
\end{tabular}

\section{Chi-Square Tests}

\begin{tabular}{|c|c|c|c|}
\hline & Value & $\mathrm{df}$ & $\begin{array}{c}\text { Asymp. Sig. } \\
\text { (2-sided) }\end{array}$ \\
\hline Pearson Chi-Square & $76.258=$ & 4 & .000 \\
\hline Likelihood Ratio & 79.507 & 4 & .000 \\
\hline $\begin{array}{l}\text { Linear-by-Linear } \\
\text { Association }\end{array}$ & 51.997 & 1 & .000 \\
\hline N of Valid Cases & 100 & & \\
\hline
\end{tabular}

\section{Bar Chart}

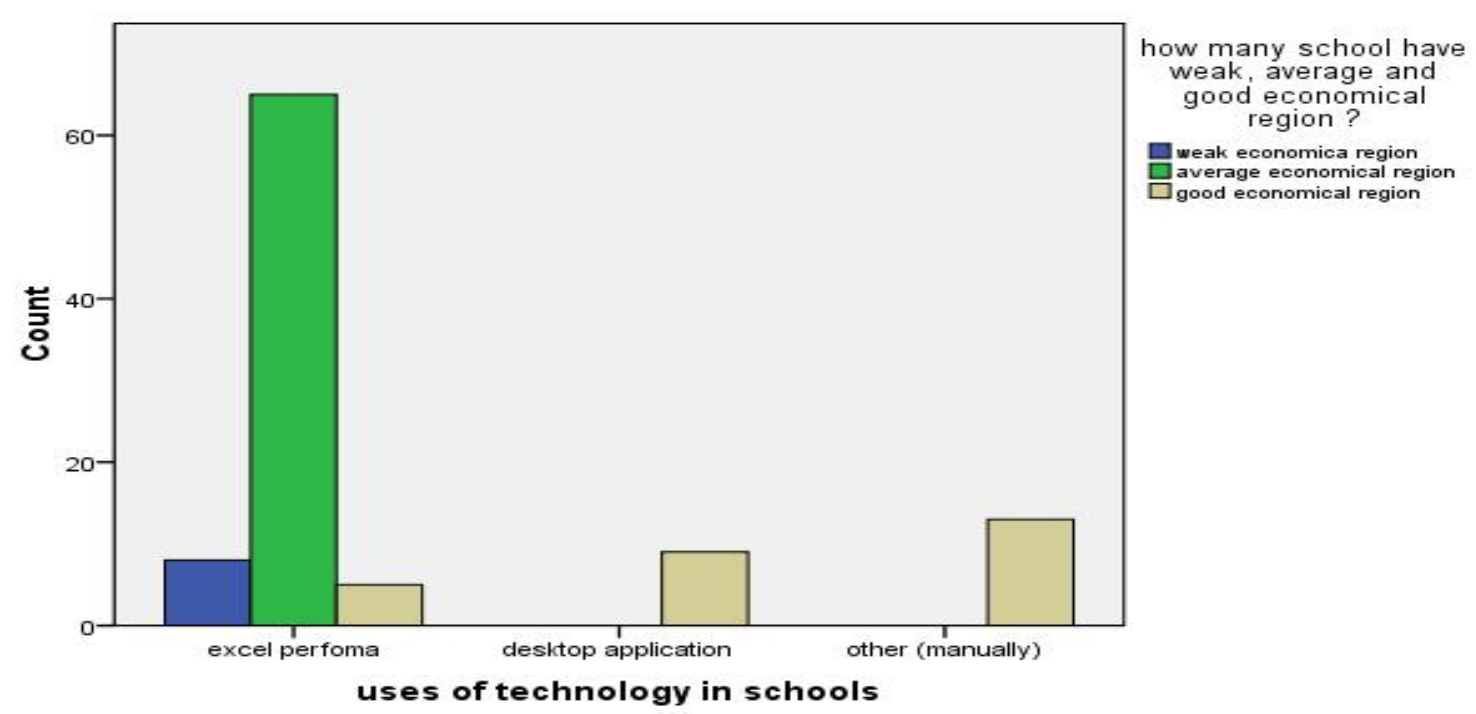

Figure6:-Represent Basic Method Excel, Desktop and manually (By Weak, Average and Good Economical school) 


\begin{tabular}{|c|c|c|c|c|c|c|}
\hline \multicolumn{7}{|c|}{ cases } \\
\hline & \multicolumn{2}{|c|}{ Valid } & \multicolumn{2}{|c|}{ Missing } & \multicolumn{2}{|c|}{ Total } \\
\hline & $N$ & Percent & $N$ & Percent & $N$ & Percent \\
\hline $\begin{array}{l}\text { how much ready for } \\
\text { advance technology? } \\
\text { how many school have } \\
\text { weak, average and good } \\
\text { economical region? }\end{array}$ & 100 & $100.0 \%$ & 0 & $.0 \%$ & 100 & $100.0 \%$ \\
\hline
\end{tabular}

how much ready for achance technology? * how mamy school hawe weak, awerage and good economical region?

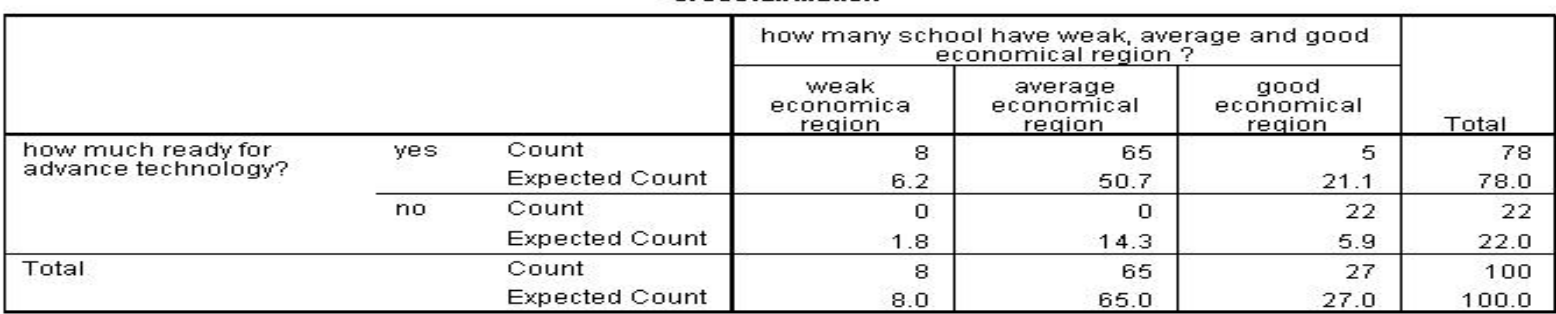

Chi-Square Tests

\begin{tabular}{|l|r|r|r|}
\hline & Value & df & $\begin{array}{c}\text { Asymp. Sig. } \\
(2-\text {-sided })\end{array}$ \\
\hline Pearson Chi-Square & $76.258^{2}$ & 2 & .000 \\
Likelihood Ratio & 79.507 & 2 & .000 \\
Linear-by-Linear & 58.364 & 1 & .000 \\
Association & 100 & & \\
Nof Valid Cases & & \\
\hline
\end{tabular}

\section{Bar Chart}

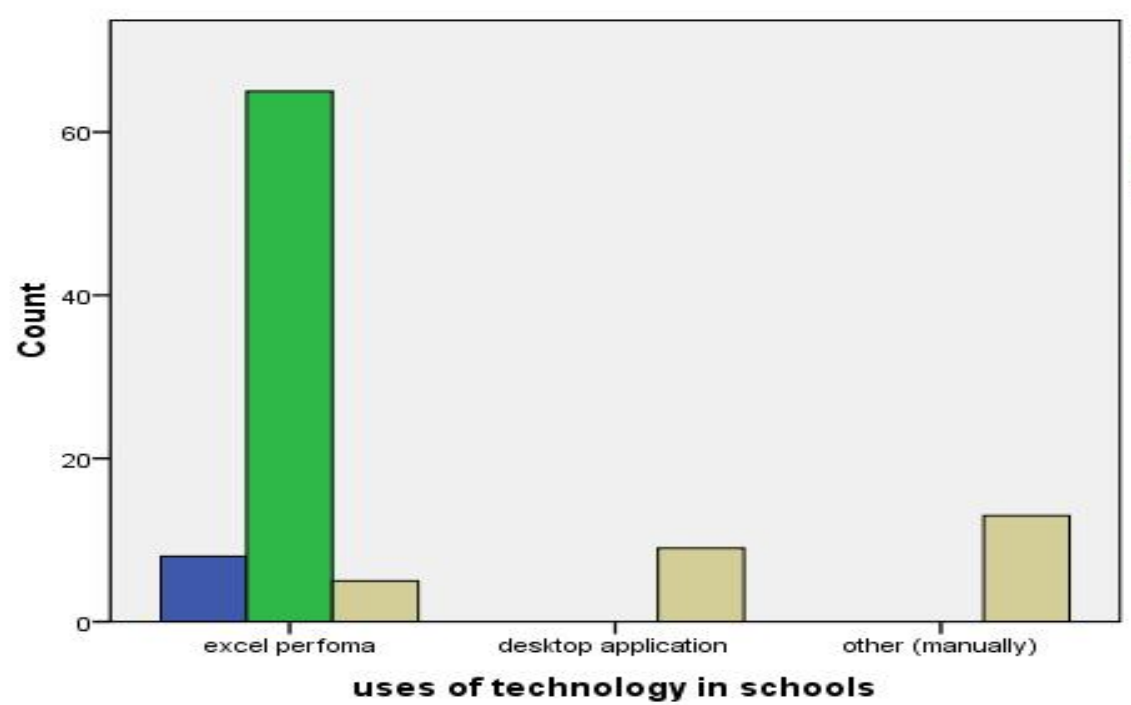

how many school have weak, average and good economical region?

weak economica region average economical region $\square$ good economical region

Figure7:-Ready for Advance Technology. (By Weak, Average and Good Economical school) 